\title{
Evaluation of Civil Flight Deck Design using Fuzzy Logic Approach
}

\author{
Negin O. Aminian ${ }^{1}$, Fairuz I. Romli ${ }^{2}$, Salim M. Salim ${ }^{3}$ \\ Department of Aerospace Engineering, \\ Faculty of Engineering, Universiti Putra Malaysia, 43400 Serdang, Selangor, Malaysia \\ 1negin_oa@yahoo.com \\ 2 fairuz_ir@upm.edu.my \\ ${ }^{3}$ salim_mkubwa@yahoo.com
}

\begin{abstract}
A good ergonomic design for cockpit can greatly help to improve pilots' task efficiency and reduce potential human errors, hence increasing safety of flight operations. The ergonomics aspect should be more emphasized nowadays as the cockpit system moves towards more flight automation, particularly regarding the human-machine interactions. In this study, the main objective is to highlight whether there is potential improvement for current cockpit system design. The evaluation process is done using fuzzy logic pattern recognition approach and three evaluation objects have been chosen, which are instrument panel, pedestal panel and pilot's seat. 14 experts are involved in evaluating these objects through a survey that has been distributed to them. 10 evaluation criteria are established for the study and cockpit designs of two existing aircraft series are used in the example case study. All in all, the results highlight that there exists some rooms for improvement for the current cockpit design that should be considered in the future to enhance its efficiency.
\end{abstract}

Keyword-Ergonomics, Fuzzy Logic, Pattern Recognition, Cockpit Design

\section{INTRODUCTION}

Cockpit is the main workstation for pilots. During each flight, all information and control panels necessary for flying the airplane and communicating with the crew have to be made easily accessible to pilots for safety purposes. For this reason, the design of cockpit interfaces is a primary and also important focus of aviation ergonomics. A good ergonomic design for the cockpit greatly help improve pilots' efficiency and also eliminate potential human errors, thus increasing safety of flight operations. However, in many designs, the reliability and safety of the onboard equipment inside the cockpit have been more emphasized than the pilots' demands and workloads. For instance, the mental workloads of pilots nowadays are considerably increased with the rising of flight automation systems due to their changing task role inside the cockpit [1]. This situation can be alleviated by improving the ergonomic design of cockpits [2], which can optimize the interactions between the pilots and the avionics technology to enhance the overall system performance [3]. It can be taken that both ergonomics and automation are among the key factors that will affect the performance of pilots in the cockpit during flight.

With the automation of many previously a pilot's tasks, the majority of designers believed that human error is no longer a big factor in safe flight operation. In addition, most pilots heavily trust the flight automation system and this dependency might lead to a loss of their mental capability to manually operate the aircraft in emergency situations. Hence careful attention to the needs of the pilots has to be placed on design and location of cockpit's instruments and panel, controls and also their seats (where pilots spend the majority of their time during flight) [4]. There have been some complaints of discomfort made by pilots with regards to the flight deck design [5]. In this regard, it is important to investigate the adequacy of the current standards for cockpit design, particularly in the context of ergonomics. The fuzzy logic pattern recognition approach can be applied to define the optimum cockpit design. In short, pattern recognition is the process of finding data structures and classifying them into categories such that design elements within a category are highly interrelated to each other but have little or no relationship with those in different categories [6]. The aim of this study is to identify any room of improvement that can be made to the current cockpit design through an evaluation process using fuzzy logic approach. This is a continuation study of a previous work that has identified some cockpit design mismatches in [7].

\section{Methodology}

The evaluation process on the cockpit design is done based on several established evaluation criteria, which cover the important design criteria in aviation and the ones that notably affect the pilot's efficiency in executing their tasks during flight. The rating for these evaluation criteria is obtained from a survey to 14 experts with vast experiences in the field, who are mostly senior aviation pilots. The obtained information is then applied in fuzzy pattern recognition approach, through which the mathematical model is derived and the nearest approach degree is established. 
In this study, two sample cases of cockpit design from existing aircraft are used. Their evaluation highlights the advantages and disadvantages of each cockpit design. Three evaluation objects have been identified within the cockpit system that are of interest. These objects play an essential role in the pilot's performance and they are the instrument panel, pedestal panel and also the pilot's seat.

\section{A. Evaluation Criteria}

Several evaluation criteria for the cockpit design have been established from literatures, standards and also a survey to several pilots. The 10 evaluation criteria chosen for this study are briefly discussed as follow:

- Ergonomics - classified into three categories: physical, cognitive and organizational characteristics. Physical is concerned with the physical and biomechanics of human characteristics. On the other hand, cognitive covers the human mental process such as interaction with the system and its elements while organizational process is concerned with optimization of socio-technical system that focuses on people.

- Adaptability - capacity of the system to be adopted in changed situations. This can be mostly achieved by adding, upgrading or replacing any component of the system.

- Maintenance - wrong system operation performed by humans at the wrong time often leads to errors. It has been reported that $18 \%$ of total aircraft accidents can be related to maintenance [8].

- Reliability - a vital and necessary aspect of aircraft system structure. It is crucial to include reliability engineering management when considering lifecycle of the aircraft.

- Safety - refer to the control design process to minimize the risks and increase the health and safety in design and operating processes. This design objective should be able to guarantee health and safety of the users over the system's lifecycle.

- $\quad$ Aesthetics - application of engineering, scientific and mathematical methods to systematically identify and quantify the roles of aesthetic factors and parameters in the system design.

- Form - covers intellectual and emotional parts of the system design. Form is embodied composition that gains from the relationship of system elements.

- Material - material used inside the cockpit must be tested to see whether it is safe to avoid any allergy or injury to pilots. For instance, non-metallic parts for the pilot's seat must comply with FAR 25.853(b).

- Technology - relationship between philosophical anthropology and human, and differences between its manifestation in the mind, through human activities and as independent objects that happen in physical or social world around us.

- $\quad$ Size - the indoor roominess of the cockpit to house the instrument, panels, seats and other controls. The size should avoid limited movement for the pilots and the panels must be easily observed especially during the emergency situation. Available degrees of freedom let the crew to easily move and control the situation.

\section{B. Evaluation Rating Scale}

The method for evaluation in this study is based on the Cooper-Harper rating scale. This Cooper-Harper or pilot rating is often used in the final step of evaluation process for quantifying the quality of the aircraft. It has already been accepted since 1969 as standard measure of quality [11]. In this rating, grade I is given for the best situation of the evaluated object, which means that the design provides satisfactory performance to the majority of the users. On the other hand, grade $\mathrm{X}$ is given as the worst assessment where the evaluated object's design has the most defects and might need to be completely redesigned. The detailed description of evaluation rating scale used in this study is as tabulated in Table I.

TABLE I. Description of the Evaluation Rating Scale

\begin{tabular}{|c|l|c|}
\hline Grade & \multicolumn{1}{|c|}{ Description } & Score \\
\hline I & $100 \%$ meet the requirements. No need any change. & 10 \\
\hline II & $90 \%$ meet most of the requirements. & 9 \\
\hline III & $80 \%$ meets the basic requirements, has some defects. & 8 \\
\hline IV & $70 \%$ meets the basic requirements but has much more defects. & 7 \\
\hline V & $60 \%$ meets the basic requirements, has defects that need some changes to improve. & 6 \\
\hline VI & $50 \%$ meet the basic requirements but near half has defects. & 5 \\
\hline VII & $40 \%$ has so much defects and need more improvement & 4 \\
\hline VIII & $30 \%$ needs too much improvement due to defects. & 3 \\
\hline IX & $20 \%$ needs to redesign some parts due to defects & 2 \\
\hline X & $10 \%$ meet none of the requirements and should be redesigned & 1 \\
\hline
\end{tabular}




\section{Fuzzy Logic Pattern Recognition}

The fuzzy logic theory was introduced in 1965 to address the uncertainty meaning of qualification linguistic words used in daily life. In fact, fuzzy logic is the mathematical analysis logic that solved many problems by assigning specific values to imprecise meaning to find the accurate result. Based on fuzzy pattern recognition, two basic operations, which are abstraction and generalization, are proposed. Abstraction means estimation of a membership function from the training samples while generalization is performed using the estimate to compute the values of the membership for unknown objects not contained in the training set [9].

Data analysis is done based on qualitative or linguistic model, where logistic terms are being used instead of the mathematical equations. Numerical values or formula are used to describe the domain for the data. For the pattern recognition process, a model that consists of the pattern environments is considered. The simple way to solve this type of problem is by template matching [10]. A template of the best pattern is identified and used as reference. Data of test pattern will then be matched to this reference pattern, point by point. For this study, the identified objects are first quantified for mathematical models of pattern recognition. Relationship between the models is then established to calculate the nearest and maximum values, and to observe how close the models are to the reference patterns. In this case, instrument panel, pedestal panel and pilot's seat are evaluated by using the standard model database and common criteria that are important in all three of them are identified. These data is then used to choose the nearest mode classification.

The approach degree is defined as the measurement of the degree of similarity between two fuzzy sets. There are many different types of approach degree that can be used such as the Lattice, Euclid and Hamming approach degrees. This study utilizes a fuzzy logic theory that is previously applied in different areas of aircraft design analysis but can also be extended to other fields of ergonomics like the cockpit design architecture in this case. For this study, approach degree of evaluation objects is calculated using Equation (1).

$$
\sigma(A, B)=\frac{\sum_{i=1}^{n}\left(a_{i} \wedge b_{i}\right)}{\sum_{i=1}^{n}\left(a_{i} \vee b_{i}\right)}
$$

$A$ and $B$ are fuzzy subsets of a domain, whereby $A$ is standard model database and $B$ is the identified object's model. For a domain $X, n$ fuzzy set of $A$ is in universe of discourse $X$, which here can correspond to instrument panel, pedestal panel and pilot's seat. As mentioned in the previous section, there are 10 indexes to be evaluated: ergonomics, adaptability, maintenance, reliability, safety, aesthetics, form, material, technology and size. Hence the standard model database, $A$ will take the matrix form as shown in (2).

$$
A=\left[\begin{array}{cccc}
a_{1,1} & a_{2,1} & \cdots & a_{10,1} \\
a_{1,2} & \ddots & & a_{10,2} \\
\vdots & & \ddots & \vdots \\
a_{1,10} & a_{2,10} & \cdots & a_{10,10}
\end{array}\right]
$$

Based on evaluation rating scale used in this study, the quantified standard model database matrix is shown in Table II.

TABLE III. Evaluation Rating for the Panels and Pilot's Seat in the Cockpit

\begin{tabular}{|c|c|c|c|c|c|c|c|c|c|c|}
\hline \multicolumn{10}{|c|}{ Standard Model Database } \\
\hline Evaluation Index & A1 & A2 & A3 & A4 & A5 & A6 & A7 & A8 & A9 & A10 \\
\hline Ergonomics & 10 & 9 & 8 & 7 & 6 & 5 & 4 & 3 & 2 & 1 \\
\hline Adaptability & 10 & 9 & 8 & 7 & 6 & 5 & 4 & 3 & 2 & 1 \\
\hline Maintenance & 10 & 9 & 8 & 7 & 6 & 5 & 4 & 3 & 2 & 1 \\
\hline Reliability & 10 & 9 & 8 & 7 & 6 & 5 & 4 & 3 & 2 & 1 \\
\hline Safety & 10 & 9 & 8 & 7 & 6 & 5 & 4 & 3 & 2 & 1 \\
\hline Aesthetics & 10 & 9 & 8 & 7 & 6 & 5 & 4 & 3 & 2 & 1 \\
\hline Form & 10 & 9 & 8 & 7 & 6 & 5 & 4 & 3 & 2 & 1 \\
\hline Material & 10 & 9 & 8 & 7 & 6 & 5 & 4 & 3 & 2 & 1 \\
\hline Technology & 10 & 9 & 8 & 7 & 6 & 5 & 4 & 3 & 2 & 1 \\
\hline Size & 10 & 9 & 8 & 7 & 6 & 5 & 4 & 3 & 2 & 1 \\
\hline
\end{tabular}




\section{III.RESULTS AND DISCUSSIONS}

The survey has been distributed to 14 different experts to evaluate the interested evaluation object (instrument panel, pedestal panel and pilot's seat) in current aircraft's cockpit design. For this study, these experts are asked to assess the cockpit design of Airbus and Boeing aircraft series, as depicted in Fig. 1 and Fig. 2, respectively. Every human-machine interface of these three evaluation objects is assessed according to the value and also the place that they are used.

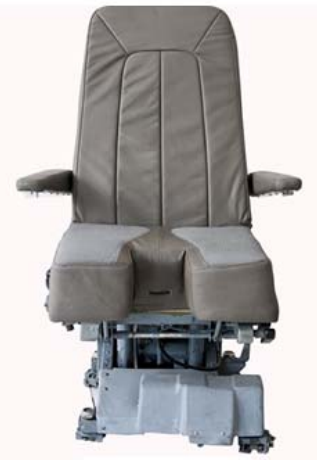

(a) Pilot Seat

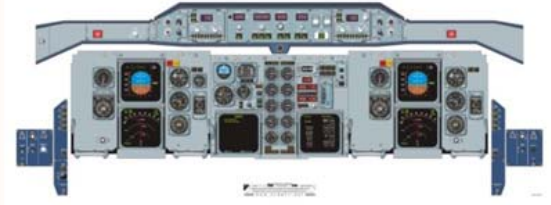

(b) Instrument Panel

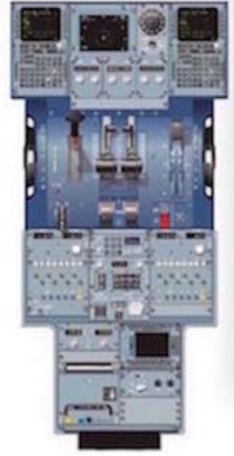

(c) Pedestal Panel

Fig. 1. Airbus A300-600 pilot seat, instrument panel and pedestal panel design [12]

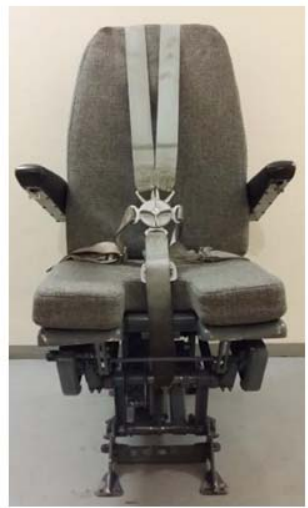

(a) Pilot Seat

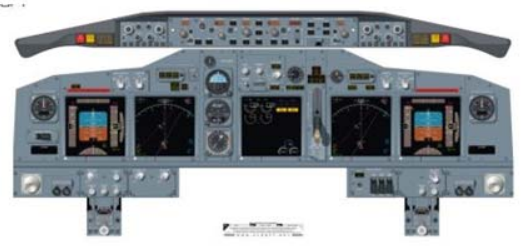

(b) Instrument Panel

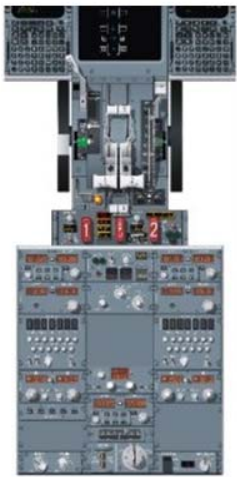

(c) Pedestal Panel

Fig. 2. Boeing 737- 800 pilot seat, instrument panel and pedestal panel design [13]

Results of expert evaluation of the instrument panel, pedestal panel and pilot's seat for the Airbus and Boeing cockpit designs are tabulated in Table III, Table IV and Table V, respectively. Table VI summarizes the average scores from the evaluation process. The resultant ratings for these two cockpit designs are then compared to the standard evaluation model and approach degrees for both cockpits are calculated using the previous equation (1). The calculated approach degrees for the two cockpit designs are listed in Table VII while Table VIII provides the overall evaluation report on the three evaluation objects.

TABLE IIIII. Subjective Evaluation Results for Instrument Panel

\begin{tabular}{|c|c|c|c|c|c|c|c|c|c|c|c|c|c|c|}
\hline \multirow{2}{*}{$\begin{array}{c}\text { Evaluation } \\
\text { Index }\end{array}$} & \multicolumn{7}{|c|}{ Airbus Cockpit Evaluation } & \multicolumn{7}{|c|}{ Boeing Cockpit Evaluation } \\
\hline & 1 & 2 & 3 & 4 & 5 & 6 & 7 & 1 & 2 & 3 & 4 & 5 & 6 & 7 \\
\hline Ergonomics & 9 & 7 & 9 & 10 & 8 & 9 & 7 & 8 & 9 & 7 & 9 & 8 & 9 & 6 \\
\hline Adaptability & 7 & 10 & 8 & 8 & 7 & 7 & 5 & 10 & 9 & 9 & 8 & 8 & 9 & 9 \\
\hline Maintenance & 9 & 10 & 8 & 9 & 10 & 10 & 8 & 10 & 8 & 9 & 7 & 9 & 10 & 9 \\
\hline Reliability & 10 & 8 & 9 & 7 & 10 & 10 & 6 & 9 & 10 & 9 & 10 & 7 & 9 & 9 \\
\hline Safety & 7 & 8 & 9 & 8 & 9 & 8 & 8 & 10 & 8 & 8 & 6 & 9 & 9 & 10 \\
\hline Aesthetics & 3 & 2 & 4 & 7 & 5 & 5 & 8 & 8 & 4 & 7 & 7 & 7 & 4 & 5 \\
\hline Form & 6 & 10 & 9 & 8 & 8 & 10 & 10 & 9 & 10 & 8 & 9 & 9 & 7 & 9 \\
\hline Material & 10 & 10 & 10 & 8 & 9 & 9 & 9 & 7 & 8 & 9 & 10 & 7 & 8 & 9 \\
\hline Technology & 10 & 9 & 7 & 10 & 9 & 6 & 8 & 8 & 6 & 6 & 10 & 8 & 8 & 9 \\
\hline Size & 9 & 9 & 9 & 9 & 5 & 7 & 9 & 5 & 4 & 10 & 8 & 6 & 9 & 7 \\
\hline
\end{tabular}


TABLE IVV. Subjective Evaluation Results for Pedestal Panel

\begin{tabular}{|c|c|c|c|c|c|c|c|c|c|c|c|c|c|c|}
\hline \multirow{2}{*}{$\begin{array}{l}\text { Evaluation } \\
\text { Index }\end{array}$} & \multicolumn{7}{|c|}{ Airbus Cockpit Evaluation } & \multicolumn{7}{|c|}{ Boeing Cockpit Evaluation } \\
\hline & 1 & 2 & 3 & 4 & 5 & 6 & 7 & 1 & 2 & 3 & 4 & 5 & 6 & 7 \\
\hline Ergonomics & 9 & 9 & 8 & 10 & 7 & 8 & 10 & 6 & 9 & 9 & 9 & 8 & 8 & 8 \\
\hline Adaptability & 8 & 7 & 9 & 9 & 8 & 10 & 9 & 9 & 10 & 8 & 9 & 9 & 9 & 10 \\
\hline Maintenance & 9 & 10 & 9 & 9 & 10 & 7 & 10 & 10 & 9 & 7 & 9 & 9 & 10 & 8 \\
\hline Reliability & 10 & 9 & 9 & 8 & 9 & 10 & 9 & 9 & 10 & 8 & 10 & 10 & 10 & 10 \\
\hline Safety & 9 & 10 & 9 & 10 & 9 & 10 & 9 & 10 & 10 & 10 & 9 & 10 & 8 & 8 \\
\hline Aesthetics & 6 & 3 & 5 & 7 & 8 & 5 & 5 & 7 & 2 & 3 & 9 & 9 & 7 & 8 \\
\hline Form & 10 & 9 & 10 & 10 & 8 & 10 & 8 & 8 & 8 & 10 & 9 & 9 & 9 & 10 \\
\hline Material & 9 & 10 & 10 & 8 & 9 & 10 & 9 & 10 & 10 & 10 & 10 & 10 & 8 & 10 \\
\hline Technology & 10 & 10 & 7 & 9 & 9 & 7 & 10 & 10 & 8 & 8 & 10 & 10 & 9 & 10 \\
\hline Size & 9 & 10 & 9 & 9 & 7 & 10 & 6 & 7 & 6 & 5 & 8 & 9 & 9 & 8 \\
\hline
\end{tabular}

TABLE V. Subjective Evaluation Results for Pilot's Seat

\begin{tabular}{|c|c|c|c|c|c|c|c|c|c|c|c|c|c|c|}
\hline \multirow{2}{*}{$\begin{array}{l}\text { Evaluation } \\
\text { Index }\end{array}$} & \multicolumn{7}{|c|}{ Airbus Cockpit Evaluation } & \multicolumn{7}{|c|}{ Boeing Cockpit Evaluation } \\
\hline & 1 & 2 & 3 & 4 & 5 & 6 & 7 & 1 & 2 & 3 & 4 & 5 & 6 & 7 \\
\hline Ergonomics & 8 & 9 & 8 & 9 & 6 & 10 & 6 & 6 & 9 & 6 & 7 & 7 & 8 & 7 \\
\hline Adaptability & 6 & 6 & 8 & 6 & 10 & 9 & 9 & 10 & 7 & 9 & 8 & 5 & 7 & 9 \\
\hline Maintenance & 7 & 9 & 9 & 10 & 7 & 6 & 8 & 10 & 8 & 9 & 9 & 9 & 9 & 7 \\
\hline Reliability & 9 & 9 & 7 & 8 & 8 & 9 & 7 & 7 & 8 & 7 & 9 & 6 & 7 & 9 \\
\hline Safety & 9 & 8 & 10 & 10 & 9 & 8 & 9 & 10 & 9 & 7 & 8 & 9 & 9 & 9 \\
\hline Aesthetics & 7 & 8 & 4 & 7 & 6 & 3 & 7 & 4 & 6 & 5 & 8 & 5 & 9 & 3 \\
\hline Form & 10 & 4 & 9 & 9 & 9 & 9 & 8 & 10 & 10 & 10 & 9 & 6 & 10 & 10 \\
\hline Material & 9 & 10 & 10 & 8 & 10 & 10 & 10 & 10 & 9 & 10 & 9 & 9 & 10 & 10 \\
\hline Technology & 10 & 10 & 9 & 10 & 9 & 10 & 10 & 10 & 10 & 10 & 9 & 10 & 9 & 10 \\
\hline Size & 7 & 5 & 8 & 7 & 5 & 9 & 10 & 9 & 9 & 5 & 8 & 10 & 3 & 4 \\
\hline
\end{tabular}

TABLE VI. Summary of Average Evaluation Score

\begin{tabular}{|c|c|c|c|c|c|c|}
\hline \multirow{2}{*}{ Evaluation Index } & \multicolumn{2}{|c|}{ Instrument Panel } & \multicolumn{2}{c|}{ Pedestal Panel } & \multicolumn{2}{c|}{ Pilot's Seat } \\
\cline { 2 - 7 } & Airbus & Boeing & Airbus & Boeing & Airbus & Boeing \\
\hline Ergonomics & 8.42 & 8.00 & 8.71 & 8.14 & 8.42 & 7.57 \\
\hline Adaptability & 7.42 & 9.14 & 9.14 & 8.57 & 6.57 & 7.85 \\
\hline Maintenance & 9.14 & 8.85 & 9.14 & 8.85 & 8.14 & 8.71 \\
\hline Reliability & 9.42 & 9.00 & 9.14 & 9.57 & 8.14 & 7.57 \\
\hline Safety & 8.14 & 8.57 & 9.14 & 9.28 & 9.00 & 8.71 \\
\hline Aesthetics & 4.85 & 6.00 & 4.71 & 5.57 & 6.00 & 5.71 \\
\hline Form & 8.71 & 8.71 & 9.28 & 9.00 & 8.28 & 8.28 \\
\hline Material & 9.28 & 8.28 & 9.28 & 9.71 & 9.57 & 9.42 \\
\hline Technology & 8.42 & 7.85 & 8.85 & 9.28 & 9.71 & 9.71 \\
\hline Size & 8.14 & 7.00 & 8.57 & 7.42 & 7.28 & 6.85 \\
\hline
\end{tabular}

TABLE VII. Calculated Approach Degrees

\begin{tabular}{|c|c|c|c|c|c|c|c|c|c|c|c|c|}
\hline \multirow{2}{*}{$\begin{array}{c}\text { Evaluation } \\
\text { Object }\end{array}$} & \multirow{2}{*}{$\begin{array}{c}\text { Cockpit } \\
\text { Design }\end{array}$} & \multicolumn{10}{|c|}{ Approach Degree to Grades I - X } & \multirow{2}{*}{ Results } \\
\hline & & I & II & III & IV & $\mathrm{V}$ & VI & VII & VIII & IX & $X$ & \\
\hline \multirow{2}{*}{$\begin{array}{c}\text { Instrument } \\
\text { Panel }\end{array}$} & Airbus & 0.82 & 0.89 & 0.89 & 0.81 & 0.71 & 0.61 & 0.49 & 0.37 & 0.24 & 0.12 & $\mathrm{~V}$ \\
\hline & Boeing & 0.81 & 0.90 & 0.91 & 0.84 & 0.73 & 0.61 & 0.49 & 0.37 & 0.25 & 0.12 & VI \\
\hline \multirow{2}{*}{$\begin{array}{c}\text { Pedestal } \\
\text { Panel }\end{array}$} & Airbus & 0.86 & 0.93 & 0.86 & 0.77 & 0.67 & 0.58 & 0.47 & 0.35 & 0.23 & 0.12 & V \\
\hline & Boeing & 0.86 & 0.93 & 0.87 & 0.79 & 0.67 & 0.59 & 0.47 & 0.35 & 0.23 & 0.12 & $\mathrm{~V}$ \\
\hline \multirow{2}{*}{ Pilot's Seat } & Airbus & 0.81 & 0.87 & 0.94 & 0.84 & 0.74 & 0.62 & 0.49 & 0.37 & 0.25 & 0.12 & VI \\
\hline & Boeing & 0.80 & 0.87 & 0.89 & 0.87 & 0.75 & 0.62 & 0.50 & 0.37 & 0.25 & 0.12 & V \\
\hline
\end{tabular}


TABLE VIII. Overall Evaluation Report

\begin{tabular}{|c|c|c|c|}
\hline Evaluation Object & Cockpit Design & $\begin{array}{c}\text { Resultant } \\
\text { Grade }\end{array}$ & $\begin{array}{c}\text { Synthetical } \\
\text { Evaluation }\end{array}$ \\
\hline \multirow{2}{*}{ Instrument Panel } & Airbus & V & \multirow{2}{*}{ Defects Identified } \\
\cline { 2 - 3 } & Boeing & VI & \multirow{2}{*}{ Defects Identified } \\
\hline \multirow{2}{*}{ Pedestal Panel } & Airbus & V & \multirow{2}{*}{ Defects Identified } \\
\cline { 2 - 3 } & Boeing & V & VI \\
\cline { 2 - 3 } Pilot's Seat & Airbus & V & \\
\cline { 2 - 3 } & Boeing &
\end{tabular}

From the results, the design of instrument panel of the cockpit onboard the Boeing aircraft series has received better rating than that in Airbus aircraft series. The latter design has more identified defects and is comparatively weaker in several aspects. Meanwhile, the assessment for the pedestal panel shows rather close match between the two aircraft cockpit designs. This is reflected by the same rating or amount of defects that have been derived from the evaluation rating and the calculated approach degree for both designs. Last but not least, for pilot's seat design, the one onboard the Airbus aircraft series has been rated higher than that on the Boeing aircraft series. The experts were more satisfied with the pilot's seat design on Airbus aircraft series and they felt that it is much more comfortable to sit on during the flight.

\section{IV.CONCLUSION}

The pilots' performance nowadays is heavily dependent on the effective design of the cockpit, particularly in terms of ergonomics in human-machine interaction. In this study, the cockpit system architecture of two existing aircraft series is assessed based on fuzzy pattern recognition theory. This is done to highlight any deficiency and potential improvement of the current cockpit design to enhance the pilots' task efficiency during flight. Based on the results, it can be concluded that both sampled cockpit designs have their own advantages and disadvantages compared to each other. Nonetheless, the overall evaluation score of these two designs also indicates that there are still room for improvement that can be done to increase their effectiveness. Future work on this research area might include identification of the specific design defects of the overall cockpit system instead of just the three evaluation objects chosen in this study.

\section{REFERENCES}

[1] N. Othman, F. I. Romli, Mental Workload Evaluation of Pilots Using Pupil Dilation, International Review of Aerospace Engineering (2016), 80-84

[2] H. Zhang, D. Zhuang, F. Wu, The Study on Pleasure and Ergonomics of Cockpit Interface Design, IEEE 10th International Conference on Computer-Aided Industrial Design \& Conceptual Design (2009)

[3] I. Cimpian, Ergonomic Design of Aircraft Cockpit, Journal of Industrial Design \& Engineering Graphics (2012), 25-28

[4] D. Strickland, B. Pioro, C. Ntuen, The Impact of Cockpit Instruments on Pilot Exhaustion, Computers \& Industrial Engineering (1996), 483- 486

[5] R. Goossens, C. Snijders, T. Fransen, Biomechanical Analysis of the Dimensions of Pilot Seats in Civil Aircraft, Applied Ergonomics (2000), 9-14

[6] G. Klir, B. Yuan, Fuzzy Sets and Fuzzy Logic (Prentice Hall, New Jersey, 1995)

[7] N. O. Aminian, F. I. Romli, S. Wiriadidjaja, Usability Evaluation Survey for Identifying Design Issues in Civil Flight Deck, IOP Conference Series: Earth and Environmental Science (2016)

[8] B. S. Dhillon, Human Reliability and Error in Transportation Systems (Springer, Berlin, 2007)

[9] S. Mitra, S. K. Pal, Fuzzy Sets in Pattern Recognition and Machine Intelligence, Fuzzy Sets and Systems (2005) 381-386

[10] S. K. Pal, A. Pal, Pattern Recognition: From Classical to Modern Approaches (World Scientific, Singapore, 2001)

[11] R. P. Harper, G. E. Cooper, Handling Qualities and Pilot Evaluation, Journal of Guidance, Control and Dynamics (1986), 515-529

[12] (2017) The SkyART website. [Online]. Available: www.skyart.com

[13] (2017) The AircraftSeat24 website. [Online]. Available: http://www.aircraftseats24.com

\section{AUTHOR PROFILE}

Negin O. Aminian graduated with Master's degree in Innovation and Engineering Design from Universiti Putra Malaysia in 2012. She is now pursuing her PhD degree at Aerospace Engineering Department, Universiti Putra Malaysia.

Fairuz I. Romli earned his PhD in Aerospace Engineering from Georgia Institute of Technology, Atlanta, USA in 2009. He currently works as Senior Lecturer in Department of Aerospace Engineering, Universiti Putra Malaysia, Malaysia. His research interests include aerospace system design tools and methodologies, statistical analysis and air traffic management.

Salim M. Salim graduated with Master's degree in Engineering Management from Universiti Putra Malaysia in 2013. He is now pursuing his PhD degree at Aerospace Engineering Department, Universiti Putra Malaysia. 